\title{
Analysis of a structural and logical model of a leading company's financial standing
}

\author{
Marina Charaeva \\ Management department \\ Southern Federal University \\ B.Sadovaya str., 105/42, 344006 Rostov-on-Don \\ Russian Federation \\ e-mail: mvcharaeva@mail.ru
}

\begin{abstract}
Analytical work is actualized in the context of macroeconomic instability when the interpretation of findings makes possible determining the level of company's financial standing, since in today's economy it is the most important characteristic of business activity and reliability of the company. It determines its competitiveness and business cooperation prospects. Moreover, it is the guarantor of effective realization of economic interests of all economic participants and determines the leading position of a company on the market. This paper presents methods of financial standing evaluation and a structural and logical model that will remove contradictions in choosing the financial indicators. Its practical application will provide streamlining the evaluation process and improve its quality. Obviously, that only an adequate financial condition evaluation will promote the effective strategic development of the company. All this leads to the need for updating the studies related to the choice of financial indicators and financial standing analysis. The subject of the study is financial and economic relations that determine the results of the financial condition of the company. The purpose of the study is to develop a structural and logical model for analyzing the financial condition of an enterprise. The methods used in this study are dialectical cognition of reality, systemic analysis, structural analysis, deduction and induction that provide a comprehensive interpretation of the findings. Based on our results, a stage-by-stage analysis of the financial condition was formed, and key financial indicators were identified, thus providing a reliable evaluation and effortless interpretation of the results obtained. It appears that theoretical and methodological developments could be utilized by enterprises to improve the effectiveness of financial analysis through the application of practice-oriented aspects of results' interpretation. Our results deepen and supplement the theoretical basis of financial management in the financial standing analysis, develop the methodological foundations of research and have a great potential for practical implementation.
\end{abstract}

\section{Introduction}

In modern economy, the management of financial standing of the company and the methods of its evaluation are the most important peculiarities of effective business organization and improving the efficiency of its operation. Insufficient attention to this problem could lead to unprofitable activity of the company, decrease in competitiveness and even to its bankruptcy (Vasilieva and Okhrimenko 2017).

Good financial standing is the most important condition for effective and prosperous business activity. To achieve this, permanent solvency, liquidity, financial sovereignty and high management efficiency should be ensured (Balcerzak et al. 2017). Financial condition reflects the company's ability to finance its current activities and development, constantly maintain its solvency and investment appeal. To do this, the company should have sufficient capital, an optimal structure of assets and funding sources. It is equally important to apply funds in a way that revenues exceed expenditures, thus ensuring stable solvency and increasing profitability (Ansimova 2014; Kalyugina et al. 2015; or Ushakov et al. 2017).

Financial condition depends on the company's performance, its commercial and financial activities. Successful implementation of production and financial plans positively affects the financial state. And, on the contrary, as a result of failing to complete the plan for the production and sales, we could observe the increase in production costs, the reduction in revenue and profit margins, and, as a consequence, deterioration of financial condition and solvency leading to possible bankruptcy. Thus, effective application of resources, increasing production and sales of products, reducing the cost are the basis for increasing profits and forming financial resources in the amount needed to expand the production activities (Koudelková and Svobodová 2014; Č́belková et al. 2015; Balahadze and Bezrukov 2015; Gavurova et al. 2017; Mackevičius et al. 2018; or Teresienè 2018).

Sustainable financial condition is formed throughout the company's economic activity, its assessment provides the answer to the questions of how correctly the enterprise manages financial resources, how it utilizes the property, what is the structure of this property, how rationally it combines its own and debt funds, how 
effectively it employs its own capital, what is the return on the production capacity, what are the relationships with debtors, creditors, budget, shareholders, etc? To the contrary, ineffective assets' management and lack of funds lead to deficiencies in the provisions with the necessary resources and, consequently, cause drop in sales and profits.

Therefore, the financial activity of the company is aimed at ensuring the systematic inflow and spending of monetary resources, the execution of accounting discipline, the achievement of rational proportions of own and debt capital and its effective application. The key goal of financial activity is a decision of where, when and how to apply financial resources as efficiently as possible to develop production and maximize profits.

In this vein, financial condition of the company is the most important feature of its business activity and reliability. It determines the competitiveness of the company, its capabilities in business cooperation, acts as the guarantor of fruitful activity of the company and its partners. In modern conditions, a real assessment of the financial conditions is of great importance not only for the entities themselves, but also for shareholders and potential investors. Therefore, analytical work concerned with studying and forecasting of company's financial condition, becomes of great importance. Early and precise recognition of vulnerabilities of the company's finances provides the implementation of measures aimed at preventing its possible bankruptcy. Topical is the issue of assessing the structure of the balance sheet, since its poor condition indicates the insolvency of the company.

Financial condition is characterized by the placement and circulation of company's funds. This information is presented in the balance sheet. The key factors determining the financial condition of the company include, firstly, the implementation of the financial plan and replenishment, as the need arises, of equity capital on the profit and, secondly, the turnover rate of working capital (Chabannyi 2016; Isavnin and Farkhutdinov 2017).

Financial condition reflects the organization's ability to finance its current activities on an expanded basis, as well as constantly maintain its solvency and investment capacity. To this end, the enterprise should have sufficient capital and optimal structure of assets and funding sources. It is equally important to apply funds in a way that incomes constantly exceed expenditures, thereby ensuring stable solvency and increasing profitability.

Financial standing of the company shows the final results of its activity. Thus, final results are of certain interest to owners (shareholders), business partners, tax authorities. All this predetermines the importance of analyzing the financial standing of economic entities and enhances the role of the analysis throughout the economic process.

\section{Leadership and leadership styles}

Financial condition is characterized by a system of indicators reflecting the real and potential financial capabilities of the company as an investment object for capital and the taxpayer. Good financial condition is the result of effective resources' utilization, the ability to be liable for the debts, sufficiency of own funds to exclude high risk, stable prospects for profit (Białowąs 2018). Unsatisfactory financial condition results in low efficiency of resources' utilization, unprofitable allocation of funds. The extreme case of a low financial condition level is the threat of bankruptcy, the inability of the company to be liable for its debts (Savitskaya 2016).

The assessment of financial condition is a recognized tool for identifying the unfavorable situation in the company's business activity. It gives an opportunity not only to ascertain the improvement or deterioration of the company's position, but also to assess the probability of its bankruptcy (Negashev 2013).

Application of a comprehensive analysis of the company's financial condition generates real grounds for the effective management of the financial condition, a positive impact on the key activity indicators to improve the company's financial climate (Kartseva and Bondarenko 2017).

Assessment of company's financial condition is based on the analysis of business background through evaluating parameters of its functioning and matching them with references and a number of similar indicators of competitors. This analysis is intended to disclose the content of economic factors affecting the enterprise and is aimed at understanding the results and consequences. Its application helps identifying weaknesses (possible trouble spots), as well as identifying its strengths to rely upon in the future (Sterhov 2016). Moreover, it provides a comparative assessment of the company's financial condition in the context of certain gaps or other enterprises. Notable that the methods of analysis do not have absolute accuracy, since the estimate is always relative.

Financial standing analysis is a flexible tool in the hands of the company's managers. The purpose of the analysis is to assess the financial situation and to carry out improvement works. The findings give an answer to the question, what are the ways to improve the quality of the financial state of the company in a certain period of its activities.

Financial standing analysis (or financial analysis) is an essential ground for successful management of its finances. Under market conditions, the importance of financial standing management and its evaluation has not only increased, but also has changed qualitatively. This is caused primarily by the fact that financial analysis has 
emerged from the ordinary chain of economic analysis into the key tool of managing the financial condition of the company.

Financial analysis includes obtaining an objective assessment of financial and economic performance of the company relating to the information needs of users in order to further improve and stabilize it on the basis of main trends of future development forecasting methodology. This analysis consists of two closely interrelated sections: financial analysis and production management analysis. This distinction is somewhat formal, because internal analysis could be considered as a continuation of external analysis and vice versa. For the cause, both types of analysis could supply each other with information needed.

Financial analysis based only on the accounting data acquires the nature of external analysis, i.e. analysis conducted outside the enterprise by its interested counterparties, owners or government agencies. This analysis contains only a very limited part of information about the company's activities and does not provide disclosing all recipes for success of the entity.

There is a variety of economic information on the companies' activities and numerous ways to analyze it. Financial analysis based on the financial accounting data is called the classic way of analysis. Internal analysis utilizes other data of system accounting, technical data on the production, regulatory and planning information, etc.

The subject of internal financial analysis could be supplemented with other points that are important for the optimization of management, such as the analysis of capital outlay efficiency, the analysis of the relationship between costs, turnover and profits. The system of internal management analysis provides for deepening of financial analysis through employing the data from management production accounting. In other words, a comprehensive economic analysis and assessment of business performance could be carried out. The issues of financial and production analysis are closely interrelated in the context of business plans' justification and monitoring of their implementation, in the system of marketing, i.e. in the system of production management and sales, market-oriented works and services (see Potrikhaylov 2016).

In the process of research, the methods were used as follows: theoretical (analysis, synthesis, concretization, generalization, method of analogies); diagnostic (the method of tasks and tasks); empirical (the study of regulatory documents and the experience of enterprises in conducting financial analysis). The study was carried out in three stages:

- at the first stage, the study of theoretical grounds of financial standing analysis was carried out, the problem, purpose, and research methods were emphasized, a plan for applied research was compiled;

- at the second stage included identifying of problems that narrowed the application of existing methods for analysis; an experimental work was carried out; the conclusions obtained in the course of the experimental work were analyzed, tested and clarified; a structural and logical model for analyzing the company's financial standing was developed;

- at the third stage, the experimental work was completed, theoretical and practical conclusions were refined, the results obtained were generalized and systematized.

\section{Models of financial analysis}

Financial analysis is carried out using numerous models that provide arranging and identifying the relationships between the key indicators. Three main types of models are distinguished: descriptive, predicative and normative ones.

Descriptive models are the key ones in assessing the company's financial condition. These include: systems of performance balances, presentation of financial statements from various perspectives, vertical and horizontal analysis of reporting, system of analytical coefficients, analytical notes for reporting. All these models are based on the application of accounting data.

The system of analytical ratios is the leading element of financial standing analysis applied by various groups of users: managers, analysts, shareholders, investors, creditors, etc. Dozens of these indicators are known, so they are divided into several groups. Most often, five groups of indicators are distinguished in the following fields of financial analysis:

1. Liquidity analysis. Its indicators provide description and analysis of the company's capability to be liable for its debts. The idea of matching current assets (working capital) with short-term liabilities lies in the basis of indicators' calculation algorithm. The calculation results determine whether the enterprise is sufficiently provided with working capital necessary for settlements with creditors in respect of current operations. Since different types of working capital have varying degrees of liquidity (capability of rapid conversion into absolutely liquid funds i.e. cash), a number of liquidity ratios is calculated.

2. Current activity analysis. From the standpoint of funds' circulation, the activity of any company is a process of continuous transformation of certain types of assets into others:

$$
\ldots \rightarrow \mathrm{CR} \rightarrow \mathrm{RS} \rightarrow \mathrm{GP} \rightarrow \mathrm{FG} \rightarrow \mathrm{FL} \rightarrow \mathrm{CR} \ldots,
$$


where CR - cash resources; RS - raw material stock; GP - goods in process; FG - finished goods; FL float.

The efficiency of current financial and business activities could be assessed basing on the duration of the operational cycle, which depends on the turnover of funds in various assets. With other things being equal, the acceleration of turnover indicates an increase in efficiency. Therefore, the key indicators of this group are material, labor and financial resources utilization ratios: output, return on assets, stock and float turnover ratios.

3. Financial sustainability analysis. These indicators reveal the composition of the funding sources and the dynamics of standing. The analysis is based on the fact that funding sources differ in price of capital, the degree of accessibility, the level of reliability and the risk extent.

4. Profitability analysis. Indicators of this group are designed to assess the overall effectiveness of investments in the company. In contrast to the indicators of the second group, they are abstracted from specific types of assets and analyze the profitability of the capital as a whole. Therefore, the key indicators are the return on assets and the return on equity.

5. Capital markets' standing and activity analysis. In this framework, spatio-temporal comparisons of indicators characterizing the position of the company on the securities market are performed: dividend yield, earnings per share, share value, etc. This analysis is performed mainly in exchange-listed companies. Any enterprise that has idle cash and wants to invest them in securities, also focuses on these indicators.

Predictive models are the ones of forecasting and prognostic nature. They are used to forecast the company's revenues and its future financial condition. The most common of these are: the calculation of breakeven sales point, drawing up forecasting financial statements, models of dynamic analysis (rigidly deterministic factor models and regression models), situational analysis models.

Normative models provide comparison of actual activity results with expected ones calculated on the budget. These models are used mainly in internal financial analysis. Their essence comes to the establishment of standards for each expenditure item on technological processes, types of products, responsibility centers and to the analysis of deviations of actual data from these standards. The analysis is largely based on the application of rigidly deterministic factor models.

In the course of study, the following feature was revealed: a number of large audit firms and other companies engaged in analytical reviews, forecasting and consulting use analytical criteria for their assessments. Positively, it has its drawbacks. It is much easier to make a decision under single-criterion conditions than resolving multicriterial objectives. However, any prognostic decision of this kind, regardless of the number of criteria, is subjective, and the calculated values of the criteria are more of "information to consider" nature than the incentive for making immediate decisions.

As an example, we could provide the recommendations of the Committee on Compilation of Auditing Practices (UK) containing a list of critical indicators to assess the possible bankruptcy of an enterprise. We could recommend the following two-level system of indicators, considering the developments of Western audit firms and refracting these developments to the domestic specifics of doing business.

The first group includes criteria and indicators, which unfavorable current values or the emerging dynamics indicate significant financial difficulties that may occur in the foreseeable future, including the bankruptcy:

- $\quad$ recurring significant losses in the main production activity;

- excessing of critical level of overdue accounts payable;

- $\quad$ excessive use of short-term borrowed funds as funding sources of long-term investments;

- $\quad$ stably low values of liquidity ratios;

- $\quad$ persistent shortage of current assets;

- the share of borrowed funds steadily increasing to dangerous levels in the total amount of funding sources;

- incorrect reinvestment policy;

- $\quad$ excessing borrowed funds over the limits established;

- persistent default on obligations of investors, creditors and shareholders (regarding the timely repayment of loans, interest payments and dividends);

- high share of overdue accounts receivable;

- availability of excess and stale goods and production stocks;

- deterioration in relations with banking system institutions;

- forced application of new financial resources on relatively unprofitable terms:

- utilization of equipment with expired service life in the production process;

- potential losses of long-term contracts;

- adverse changes in the portfolio of orders. 
The second group includes criteria and indicators, which unfavorable values do not give grounds for considering the current financial condition as critical. At the same time, they indicate that the situation could sharply worsen under certain conditions, circumstances or failure to take effective measures. These indicators include:

- loss of key administrative staff, forced stops, as well as derangements in the production and technological process;

- insufficient diversification of the company's activities, i.e. excessive dependence of the company's financial performance on a certain project, equipment, asset, etc,;

- $\quad$ excessive interest on the possible and predictable success and profitability of the new project;

- participation of the company in litigations with unpredictable outcome;

- loss of key counterparties;

- underestimation of the need for constant technical and technological renovation of the company;

- ineffective long-term agreements;

- $\quad$ political risk connected with the enterprise as a whole or its key divisions.

In has to be mentioned that not all of considered criteria could be calculated directly on the basis of financial statements. An additional data is needed. As for the critical values of these criteria, they should be detailed in the context of industry and sub-industry, and their development could be done only after the accumulation of certain statistical data. The detailed analysis of financial condition is aimed at clarified description of the property and financial position of business entity, of the results of its activities in the past period, as well as of the company's development prospects. It clarifies, complements and expands the particular procedures of express analysis. The degree of detail depends on the analyst's intent (see Figure 1).

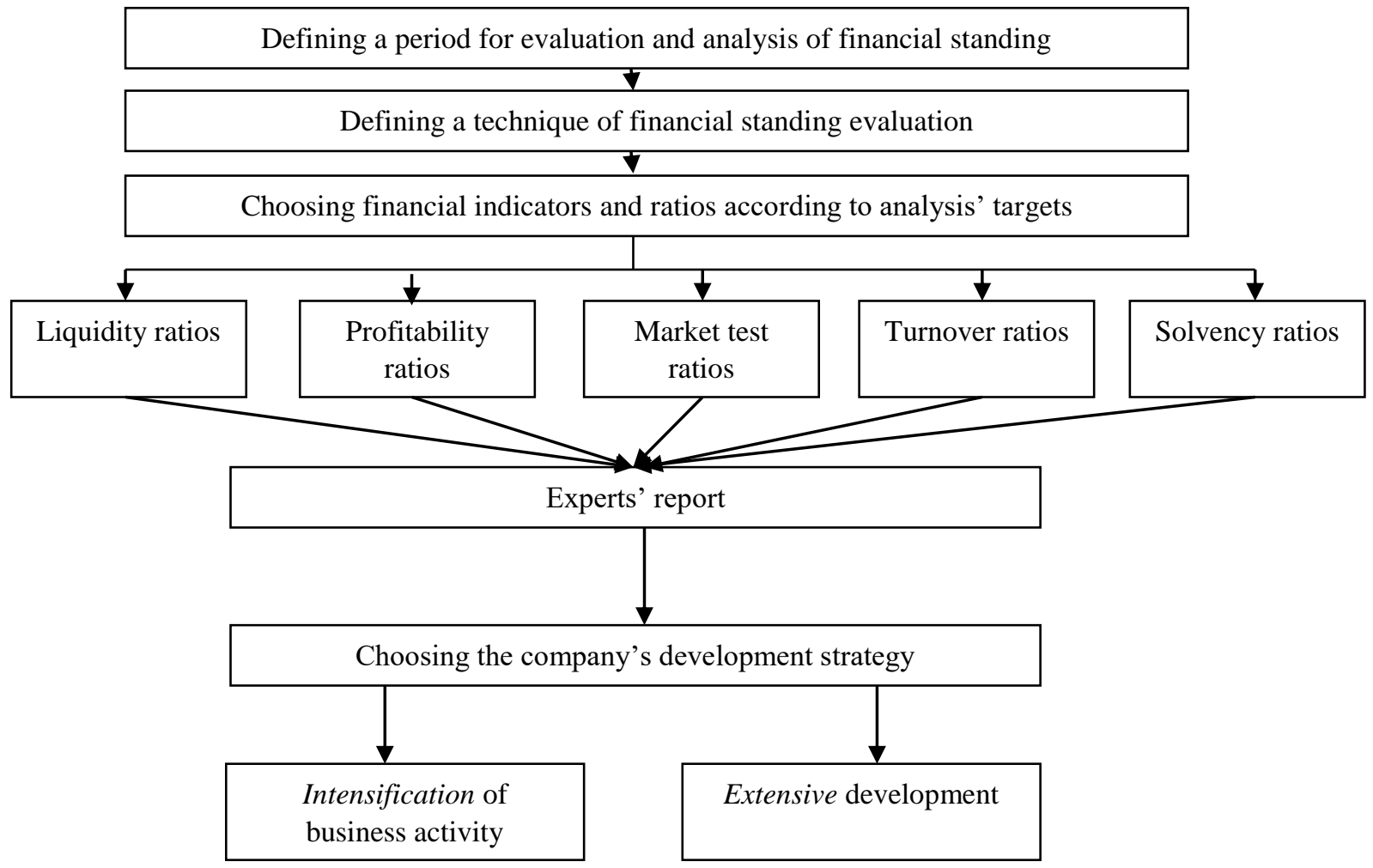

Fig. 1. Structural and logical model of company’s financial standing analysis Source: Own results

Most of the analytical methods recommended for application in internal accounting and analytical practice are considered in the textbooks and guides on economic analysis' fundamentals. Notable that the term "economic analysis' fundamentals" or "theory of economic analysis" in Russian scientific and educational literature differs significantly in meaning from the ones used in the West. In Russia, the theory of economic analysis traditionally represents a much narrower direction connected with the presentation of methods and techniques of analytical calculations at the level of a small enterprise and, as a rule, in respect of a retrospective. 
In current economic conditions, for Russian analysts, new methods of practical analysis acquire new meaning and practical importance, when making managerial decisions, assessing possible situations and taking a choice from number of alternative options. The development of a model including not only financial indicators, but also determining the logic of financial analysis, is actualized. One can call it a structural and logical model for analyzing the financial standing of a company.

Thus, when analyzing the financial state of an organization, special attention should be given to two directions: financial flows' analysis and financial ratios' analysis. The first one provides assessing the financial dynamics of the organization i.e. changes and shifts in the company's financial condition, expressed in the flows of its funds. Financial flows' analysis includes eight elements, as follows: the scope of business process' servicing, cash flows by types of economic activity and by directions of cash flows, by method of calculating amounts, by level of sufficiency, by method of evaluation in gaps, by the continuity of formation in certain period, stability of gaps of formation.

Financial ratios' analysis provides a static assessment of company's financial standing at a certain time point (for example, at the beginning or end of the month, quarter, year).

The key factors determining the financial condition are, firstly, the implementation of the financial plan and replenishment, as the need arises, of equity capital on the profit and, secondly, the turnover rate of current assets. Signal ratio that indicates the financial standing, is the company's solvency representing its ability to be liable for debts of suppliers of equipment and materials in accordance with economic contracts, loans as well as the ability to pay wages and make payments to the budget.

Since the implementation of the financial plan mainly depends on the results of production and economic activity as a whole, the set of economic factors is the most generalized indicator. Therefore, an income statement (P\&L statement) as well as other forms of reporting is involved in financial standing analysis as well.

Carrying out the financial stability assessment is related to the study of the composition, structure and dynamics of liabilities. At the same time, special attention is given to the ratio of liabilities and equity of the organization as well as to their growth and growth rates. Thus, stability is the key to survival and the basis for the sustainable position of the company.

\section{Conclusions}

All in all, we might conclude that management personnel should assess the financial condition of both the enterprise and its existing and potential counterparties to ensure the survival in modern conditions. To do this, it is absolutely necessary and crucial: a) to know the technique of assessing the company's financial standing; b) to have appropriate information support; c) to have qualified staff capable of implementing this technique in practice.

Overall, it appears that the pressing need for combining the formal and informal procedures in the process of making management decisions makes impact both on the order of analytical documents' preparation and on the sequence of financial analysis procedures: they could not be fixed once and for all, but should be adjusted throughout the process, and the discreteness of such an adjustment is a random variable. This approach once again emphasizes the feasibility of developing the structural and logical model of company's financial standing analysis. And one can immediately see that the clear understanding of the framework given will bring in line the logic of the company's activity and analytical procedures.

\section{References}

Ansimova EP (2014) Indicators of a financial condition of the organizations of branch of gas supply as parameters of the risk status of taxpayers. Taxes and taxation 2(2):184-209. doi:10.7256/18128688.2014.2.11383

Balahadze Sh, Bezrukov A (2015) Analytical evaluation of financial condition enterprises in modern conditions. Actual directions of scientific researches of the XXI century: theory and practice 3(4): 63-66. doi: $10.12737 / 14218$

Balcerzak AP, Kliestik T, Streimikiene D, Smrčka L (2017). Nonparametric approach to measuring efficiency of banking sectors in European Union countries. Acta Polytechnica Hungarica 14(7):51-70.

Białowąs P (2018) Enterprise restructuring: a quality management paradigm. Czech Journal of Social Sciences, Business and Economics 7(1):24-28. doi: 10.24984/cjssbe.2018.7.1.3 
Čábelková I, Abrhám J, Strielkowski W (2015) Factors influencing job satisfaction in post-transition economies: the case of the Czech Republic. International Journal of Occupational Safety and Ergonomics 21(4):448-456. doi: 10.1080/10803548.2015.1073007

Chabannyi AA (2016) Diagnostic methodological basis of economic results and financial analysis of the company. In: Economics and management: problems, trends and future development, pp. 99-103. doi:10.21661/r-114066

Isavnin AG, Farkhutdinov II (2017) The sourcing-based maneuver as a tool to improve the financial position of the entity. Financial analytic: problems and decisions: 534-549. doi:10.24891/fa.10.5.534

Gavurova B, Belas J, Kocisova K, Kliestik T (2017) Comparison of Selected Methods for Performance Evaluation of Czech and Slovak Commercial Banks. Journal of Business Economics and Management 18(5):852-876 doi:10.3846/16111699.2017.1371637

Kalyugina S, Strielkowski W, Ushvitsky L, Astachova E (2015) Sustainable and secure development: facet of personal financial issues. Journal of Security \& Sustainability Issues 5(2):297-304. doi: 10.9770/jssi.2015.5.2(14)

Kartseva IS, Bondarenko TH (2017) Research of various approaches to the analysis of a financial condition of the organization. Scientific dialogue: Young scientist: 9-12. doi:10.18411/spc-22-12-2017-03

Koudelková P, Svobodová P (2014) Knowledge creation \& sharing as essential determinants of SMEs innovation. International Economics Letters 3(1): 12-20. doi: 10.24984/iel.2014.3.1.3

Mackevičius J, Šneidere R, Tamulevičienè D (2018) The waves of enterprises bankruptcy and the factors that determine them: the case of Latvia and Lithuania. Entrepreneurship and Sustainability Issues 6(1):100-114. doi: 10.9770/jesi.2018.6.1(8)

Negashev EV (2013) Analytical modeling of the financial state of the company. Book published 17 Dec 2013 : 186 p. doi: $10.12737 / 1641$

Potrikhaylov ME (2016) Modern tools for carrying out the analysis of a financial condition of the enterprises. Trends of development of science and education: 156-163. doi:10.18411/1j2016-3-93

Savitskaya GV, Complex analysis of economic activity of the enterprise, $1^{\text {st }}$ edn. (Moscow, Progress, 2016), 608 p., doi:10.12737/13326

Sterhov A (2016) Analysis of the enterprise sustainability in terms of the comprehensive business security. Journal News of Irkutsk state economy academy 26 (1):57-65. doi:10.17150/1993-3541.2016

Teresienè D (2018) Performance measurement issues in central banks. Entrepreneurship and Sustainability Issues 6(1):176-189. doi: 10.9770/jesi.2018.6.1(12)

Vasilieva NK, Okhrimenko OA (2017) Analysis of factors that influence financial results of the organization. Polythematic Online Scientific Journal of Kuban State University: 1-8. doi:10.21515/1990-4665-134-052

Ushakov D, Bandurin V, Bandurin A (2017) Taxation regime as a factor of mutually intergrated macroeconomic systems' dynamics. Montenegrin Journal of Economics 13(1):171-179. doi: 10.14254/1800-5845/2017.13-1.12 